Full reference to this article: Jonsson, P., Rudberg, M., Holmberg, S. (2013), "Centralised supply chain planning at IKEA”, Supply Chain Management: An international journal, Vol. 18, No. 3, pp. 337-350.

DOI: http://dx.doi.org/10.1108/SCM-05-2012-0158

\title{
Centralised supply chain planning at IKEA
}

\author{
Patrik Jonsson \\ Department of Technology Management and Economics \\ Chalmers University of Technology \\ Gothenburg, Sweden \\ E-mail: Patrik.jonsson@chalmers.se \\ Martin Rudberg \\ Department of Science and Technology \\ Linköping University \\ Norrköping, Sweden \\ E-mail: martin.rudberg@liu.se \\ Stefan Holmberg \\ IKEA of Sweden \\ Älmhult, Sweden \\ E-mail: Stefan.holmberg@ikea.com
}

\begin{abstract}
Purpose - The purpose of this paper is to analyse the prerequisites and effects of centralised supply chain planning at IKEA, and to explore how the planning process, planning system, and planning organization make up a centralised planning approach.

Design/method/approach - The paper is based on a longitudinal case study of IKEA's implementation of global supply chain planning. The literature review generated a framework which identifies prerequisites for, approaches to, and the effects of and obstacles to centralised supply chain planning. This framework was used to analyse IKEA's supply chain planning before and after the implementation. Finally, we reflected upon the learning from IKEA and refined the framework.
\end{abstract}

Findings - A number of prerequisites for centralised supply chain planning were identified: functional products, vertical integration, a dominating organization possessing the power and competence to enforce the implementation, and the use of one planning domain possessing all critical planning information. The direct effects of centralised supply chain planning were related to supply chain integration, standardisation, specialisation, and learning effects. Implementing centralised supply chain planning in an appropriate planning context led to several operational performance improvements. Obstacles were mainly related to human and organizational, as well as to software and data issues. 
Full reference to this article: Jonsson, P., Rudberg, M., Holmberg, S. (2013), "Centralised supply chain planning at IKEA”, Supply Chain Management: An international journal, Vol. 18, No. 3, pp. 337-350.

DOI: http://dx.doi.org/10.1108/SCM-05-2012-0158

Research limitations/implications - This is a first approach towards development of a framework of how to design, use and benefit from centralised supply chain planning. The developed conceptual model, which is refined through the case study, offers some generalizability in researching centralised supply chain planning.

Practical implications - The findings show that centralised supply chain planning is a necessity for a large and growing, global supply chain striving for low-cost production and efficiency.

Originality/value - IKEA is a unique case with its supply chain characteristics and recently implemented planning concept.

Key words: planning, supply chain, information technology, centralisation, implementation, IKEA 
Full reference to this article: Jonsson, P., Rudberg, M., Holmberg, S. (2013), "Centralised supply chain planning at IKEA”, Supply Chain Management: An international journal, Vol. 18, No. 3, pp. 337-350.

DOI: http://dx.doi.org/10.1108/SCM-05-2012-0158

\section{Introduction}

This paper is concerned with when centralised supply chain planning is appropriate, what outcomes to expect, and how to achieve them. It provides a case study analysis of how IKEA, a worldwide leader in furniture retailing, has gone from decentralised to centralised planning of its network of suppliers, distribution centres, stores and forwarders. This has taken them from a fragmented management to a coordinated, centralised, supply chain planning.

A centralised supply chain planning strategy concerns common and standardised processes and working methods (Rudberg and West, 2008), centralised organization (Marcotte et al, 2009), and an integrated IT infrastructure with advanced planning and scheduling (APS) support (Jonsson et al, 2007), and may result in benefits, such as improved transparency, visibility and synchronised processes (Dreyer et al., 2009). Coordinating and managing a supply chain through centralised planning is, however, not a general solution and research identifies different prerequisites for effective centralised planning (Holmström et al., 2002; Rudberg and Olhager, 2003). Even though the right prerequisites for centralised supply chain planning exist, its implementation may result in problems or there may exist obstacles for its full implementation. Identified problems of centralised planning, for example, include incongruence of objectives and incentives of individual organizations that result in fragmented global supply chains (Pibernik and Sucky, 2007; Lorentz, et al., 2012). Most research on supply chain planning has studied individual process or organizational or IT perspectives, but few have used an integrated perspective to study all three and their effects (Power, 2005). Such an approach should be especially helpful for generating understanding of centralised supply chain planning effects and obstacles in complex supply chains (Bozarth et al., 2009) like IKEA's, which has about 30,000 sales items, 1,400 suppliers, 30 central distribution centres and 280 stores globally. Supply chain planning in the retail sector has been studied before (Wong et al., 2005), but not in a supply chain of the same magnitude as of that of IKEA.

Apart from describing IKEA's centralised supply chain planning concept, the purpose of this paper is to analyse the prerequisites, effects and obstacles of implementing centralised supply chain planning at IKEA, and to explore how the planning process, organization and planning system make up a centralised planning approach. We start with a literature review, focusing on the prerequisites for, approaches to, and effects of, implementing centralised supply chain planning, resulting in a conceptual research framework and two research questions. Next are the methodology, case study, and case analysis. Finally, we conclude the paper and provide ideas for further research. 
Full reference to this article: Jonsson, P., Rudberg, M., Holmberg, S. (2013), "Centralised supply chain planning at IKEA”, Supply Chain Management: An international journal, Vol. 18, No. 3, pp. 337-350.

DOI: http://dx.doi.org/10.1108/SCM-05-2012-0158

\section{Literature review}

Many facets of centralisation have been studied in isolation, for example, the prerequisites for a supply chain to benefit from centralisation, the expected effects on performance, and possible implementation obstacles. The literature review is centred on these areas and concludes with a conceptual research framework for analysing centralised supply chain planning, one that links the necessary prerequisites, typical concepts/approaches as well as effects/obstacles (Figure 1). The framework is used to position the two research questions, presented in the end of the literature review, and works as a structure and a theoretical base for the empirical analysis and discussion.

\subsection{Prerequisites for centralised supply chain planning}

Fisher (1997) classifies products in two categories (functional/innovative) and two supply chain categories (physical efficiency/market responsive). Innovative products should be matched with a responsive supply chain whereas functional products benefits from a physically efficient supply chain. The latter normally has a high degree of vertical integration, which in turn facilitates low-cost production through a centralised planning approach (Hayes and Schmenner, 1978; De Meyer and Vereecke, 1994; Rudberg, 2004). Rudberg and Olhager (2003) emphasize that the supply chain must be managed by, or as, a single-organization, and Rice and Hoppe (2001) highlight the need for a strong dominating organization. Centralised planning could be facilitated by limited ownership of manufacturing and full ownership of warehouses and retailers (APICS, 2011). Pibernik and Sucky (2006) exemplifies this situation with the "Supply Chain Leader", which has the power and the competence to enforce the realisation of a centrally determined supply chain plan. However, a centralised planning approach can only be implemented if one planning domain exists, which possesses all necessary information (Pibernik and Sucky, 2007), including coordination of inventory, production, and distribution decisions.

In summary (Figure 1), literature suggests that centralised supply chain planning is suitable for companies selling functional products: striving for low-cost and timely deliveries Furthermore, successful implementation of a centralised supply chain requires that a company have full control of the supply chain, through a high degree of vertical integration and/or with the aid of a dominating organization. In addition, the power and the competence of the implementing organization and the possibilities of creating a single planning domain are identified as being important prerequisites (or contextual characteristics) for implementing this approach. 
Full reference to this article: Jonsson, P., Rudberg, M., Holmberg, S. (2013), "Centralised supply chain planning at IKEA”, Supply Chain Management: An international journal, Vol. 18, No. 3, pp. 337-350.

DOI: http://dx.doi.org/10.1108/SCM-05-2012-0158

\subsection{Centralised supply chain planning}

Concepts of centralised supply chain planning can be described in many ways. This paper uses three perspectives (Figure 1): the planning processes, the planning organization and the planning system (software). These perspectives could be considered dimensions of a centralised supply chain planning concept and could either facilitate or obstruct its success.

\subsubsection{Planning processes}

Planning processes have mutual relationships and include several functions distributed hierarchically throughout a supply chain (Stadtler and Kilger, 2008). There are also relationships between different functional and organizational planning processes (Jonsson and Mattsson, 2009). Planning processes can be classified based on the length of the planning horizon and on the supply chain process that should be supported (Wortmann et al., 1997; Stadtler and Kilger, 2008). For example, the forecasting process may integrate individual forecasts from several markets and products; the sales and operations planning and master planning processes may involve several production and distribution sites; and the materials planning may integrate several warehouses. However, decisions are often distributed among a multiple number of independent decision makers along the supply chain, which leads to incongruence and imbalances on a global scale (Pibernik and Sucky, 2007). These imbalances could, however, be controlled through coordination and/or centralisation of planning responsibility. Common (standardised) working methods (Rudberg and West, 2008) and centralised organizational structures facilitate the coordination based on centralised and integrated planning processes.

\subsubsection{Planning organization}

In centralisation, decision making is often grouped in two categories (Zey-Ferrell, 1979). The first relates to decisions about regular activities facilitating an organization's output, and is about the control of the hierarchy of authority. The second regards participation in decision making and is about centralisation of decisions regarding allocation of resources. The authority in centralised organizations, thus, resides with corporate headquarters where managerial initiative and influence radiate from the centre to the periphery (The Economist Intelligence Unit, 1993). The planning resources, for example, the planning staff, are allocated centrally, and therefore decisions typically are made in an "external" decision centre that controls the whole supply chain and dictates supply chain plans for each partner in the network (Marcotte et al., 2009). Typically, the planning responsibility is more centralised in 
Full reference to this article: Jonsson, P., Rudberg, M., Holmberg, S. (2013), "Centralised supply chain planning at IKEA", Supply Chain Management: An international journal, Vol. 18, No. 3, pp. 337-350.

DOI: http://dx.doi.org/10.1108/SCM-05-2012-0158

vertically focused supply chains (Hayes and Schmenner, 1978; De Meyer and Vereecke, 1994; Caves, 1996; Rudberg, 2004) and the corporate staff must thereby play an active role in making the vertically focused organization work. A centralised planning organization and common working methods also facilitate the introduction of standardised software support, which is necessary to support decision making in global supply chains (Power, 2005; Stadler and Kilger, 2008).

\subsubsection{Planning systems}

When it comes to coordinating a vertically focused but dispersed supply chain, several drawbacks are identified with traditional Enterprise Resource Planning (ERP) systems (Stadtler and Kilger, 2008). To deal with these drawbacks, APS systems have been put forward as tools to support the coordination of global supply chains (Marcotte et al., 2009). An APS system is designed to deal with multiple sites and to include various supply chain decisions in a central planning engine. Hence, stock replenishment, distribution, production and sourcing decisions can be balanced in a centralised function aiming at optimal use of resources throughout the supply chain (Stadtler and Kilger, 2008). Since APS systems used in supply chains have to deal with multi-site environments and are based on standardised planning processes with a high degree of automation, the quality of master data and transaction data is important. The planning data must be of high quality, and data collection and validation must, consequently, be conducted in appropriate ways (Jonsson et al., 2007; Haug and Arlbjørn, 2011). Furthermore, strong coordination between the different planning modules is a must in order to achieve consistent plans for the different planning levels and different entities in the supply chain (Stadtler and Kilger, 2008).

\subsection{Effects from centralised supply chain planning}

Studies indicate that centralised supply chain planning have positive effects on business performance, especially in cost-focused supply chains (Business International, 1985; DuBois et al., 1993; Snow et al., 1993; Bartlett and Ghosal, 1998; Rudberg, 2004; Fiala, 2005; Pibernick and Sucky, 2007; Dreyer et al., 2009; Rudberg and Thulin, 2009; Marcotte et al. 2009). They also show that the performance effect may be explained by different underlying, related dimensions of centralisation (Lorentz, et al., 2012).

This paper identifies four major dimensions concerning the effects of centralised supply chain planning (Figure 1). The first dimension relates to coordination and integration (Goold and Campbell, 1987; Pibernick and Sucky, 2007). Little empirical research has been done on 
Full reference to this article: Jonsson, P., Rudberg, M., Holmberg, S. (2013), "Centralised supply chain planning at IKEA”, Supply Chain Management: An international journal, Vol. 18, No. 3, pp. 337-350.

DOI: http://dx.doi.org/10.1108/SCM-05-2012-0158

supply chain planning integration (Malhotra and Sharma, 2002; Oliva and Watson, 2011), but centralisation implies decision making on a high level and tight integration. The high level of control and coordination of activities are often identified as the main benefits (Goold and Campbell, 1987). Lack of coordination and integration may occur when decentralised decision makers ignore the overall system targets because of incomplete information or conflicting incentives (Narayanan and Raman, 2004). The second dimension is standardisation, which in the information systems literature is a means for utilising the potential of centralised planning systems within and across organizations (e.g., Bendoly and Jacobs, 2004). Specialisation is a third dimension. A centralised supply chain planning approach allows for a horizontally specialised organization (Robbins, 1990), with more planning specialists co-located. It may have positive effects on the overall skills and possibilities of managing and developing a planning process. The fourth dimension is learning effects; these can be traced in many change projects, but in a large supply chain knowledge and technology diffusion is argued to be facilitated by centralisation (Flaherty, 1996; Bartlett and Ghoshal, 1998, Rudberg and West, 2008).

Even though effects of centralised planning could be derived solely from either the planning process or the planning organization or the planning system (Figure 1), it is reasonable to believe that an approach that combines process, organization and planning system will result in the most positive effects (Power, 2005). Jonsson et al. (2007), for example, noticed that an appropriate planning organization is most likely necessary for utilising the potential of the APS system, and the commitment to the plan generated by the APS system. They also found that APS systems could improve acceptance and trust in a centralised planning organization, resulting in development of common priorities and commitment to unified plans.

\subsection{Obstacles to centralised supply chain planning}

Difficulties and problems have been identified when organizations implement and use centralised supply chain planning. Resistance to change is an often mentioned obstacle (Gargeya and Brady, 2005; van Veen-Dirks and Verdaasdonk, 2009). The centralised planning organizations' failure to achieve response to local conditions, difficulties in developing general management capabilities, and cumbersome and costly central overheads (Johnston and Scholes, 1993; Rudberg and West, 2008) can also hinder successful centralised planning. Pibernik and Sucky (2007) argued that supply chain members seldom accept centralised supply chain planning and Holmström et al (2002) argue that it is almost impossible to get a large supply chain to agree on, and implement, centralised planning and 
Full reference to this article: Jonsson, P., Rudberg, M., Holmberg, S. (2013), "Centralised supply chain planning at IKEA”, Supply Chain Management: An international journal, Vol. 18, No. 3, pp. 337-350.

DOI: http://dx.doi.org/10.1108/SCM-05-2012-0158

control. Therefore, lack of top management involvement is another possible obstacle (Bozarth, 2006; van Veen-Dirks and Verdaasdonk, 2009). Centralising planning processes and systems often result in transferring planning tasks from the planner to the system, which can lead to disagreement and resistance (Wiers, 2009). Thus, lack of user training and knowledge can be an obstacle in changing planning processes and implementing new systems (Bozarth, 2006). Human and organizational issues (Berglund and Karltun, 2007) are often considered more significant obstacles for APS system success than are the technical issues (Ivert and Jonsson, 2011). Still, technical issues like data quality problems (Jonsson et al., 2007) and integration in the information system infrastructure (Wiers, 2002; Rudberg and Cederborg, 2011) are also identified as obstacles.

\subsection{Research model and research questions}

As illustrated in Figure 1, this paper synthesises the literature review into a conceptual research model that provides a framework for analysing centralised supply chain planning. 
Full reference to this article: Jonsson, P., Rudberg, M., Holmberg, S. (2013), "Centralised supply chain planning at IKEA”, Supply Chain Management: An international journal, Vol. 18, No. 3, pp. 337-350.

DOI: http://dx.doi.org/10.1108/SCM-05-2012-0158

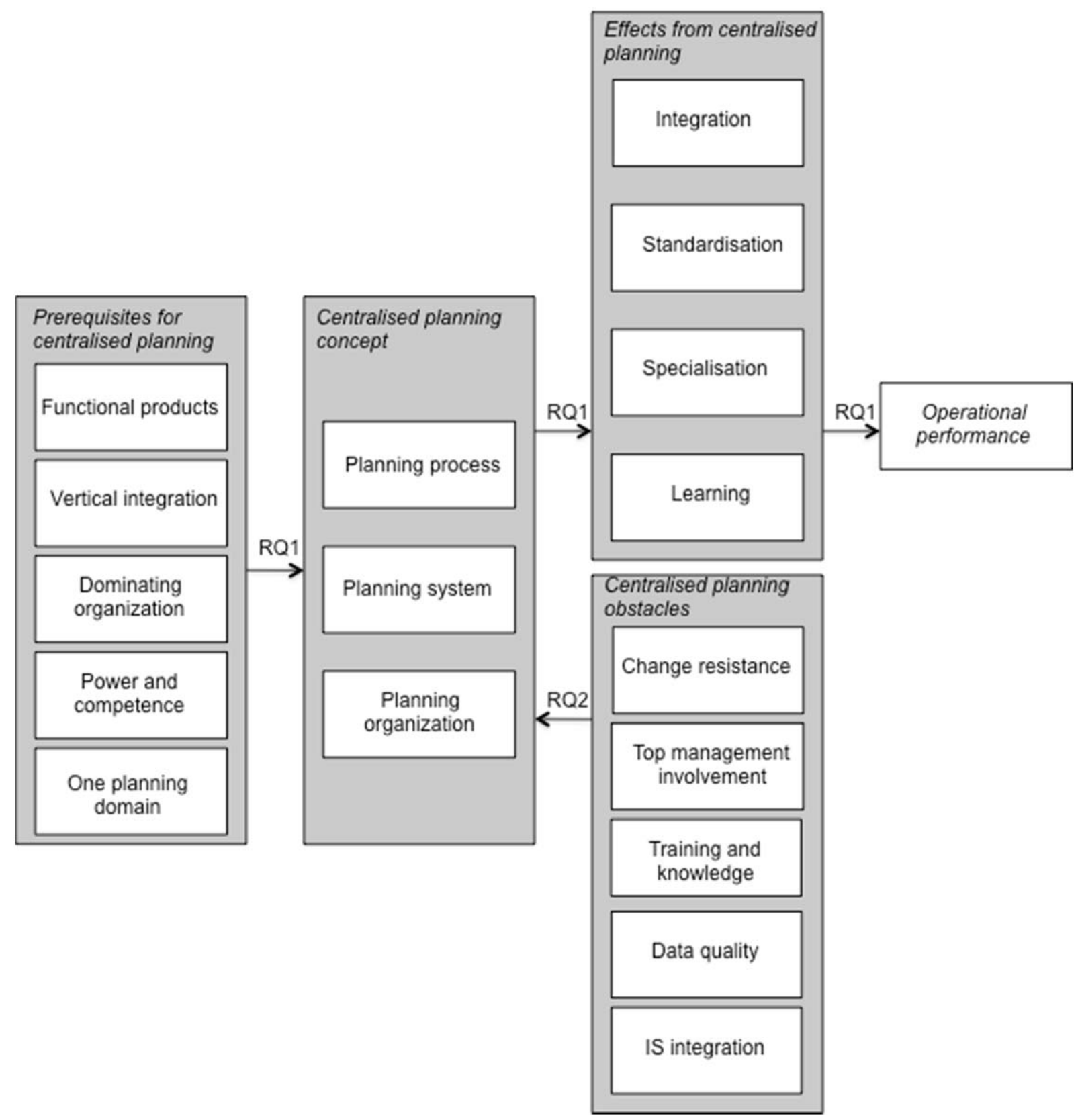

Figure 1. Conceptual research framework

The model relates the centralised supply chain planning concept (planning processes, planning system, and planning organization) to prerequisites, direct effects, operational performance and obstacles. We have also derived the following two research questions to guide the empirical analysis and discussion:

RQ1: What effects can be expected when centralising supply chain planning? 
Full reference to this article: Jonsson, P., Rudberg, M., Holmberg, S. (2013), "Centralised supply chain planning at IKEA”, Supply Chain Management: An international journal, Vol. 18, No. 3, pp. 337-350.

DOI: http://dx.doi.org/10.1108/SCM-05-2012-0158

RQ2: What are the obstacles for implementing centralised supply chain planning?

\section{Methodology}

This study is based on a single longitudinal case study (Yin, 1993; Ferlie and McNulty, 1997), at IKEA. We studied and compared IKEA's supply chain planning approach before and after it implemented its centralised supply chain planning concept. The change occurred in stages between 2000 and 2011. The 'old' planning approach refers to the situation prior to 2003. The 'new' concept refers to the situation after 2010. IKEA is considered to have supply chain characteristics suitable for applying a centralised planning concept, which is why it was appropriate for testing and further developing the framework outlined in the literature review. The study could be considered unique (Yin, 1993) because IKEA is rather unusual with its unique supply chain characteristics and its recently implemented planning concept. The case study describes IKEA's global supply chain planning concept and explores how the processes, organization and planning systems make up a centralised planning concept. The case analysis is used to discuss the characteristics of the centralised planning concept, focusing on the two research questions. The empirical scope is the planning of the material flow of IKEA's supply chain from supplier through distribution centres (DCs) to stores. The unit of analysis is its tactical and operational supply chain planning (processes, organization and software).

\subsection{Data collection}

Different methods were used to collect data: in-depth interviews, observations, and company documents. Three researchers collected the data, did the analysis and wrote the paper; two were external to IKEA and the third worked at IKEA and was involved in the planning and rollout of the concept. The internal researcher's role was to take field notes, collect relevant internal documents, write a draft description of the two planning concepts (prior to 2003 and after 2010) and give the two principal researchers access to data and to people to interview so they could finalize the case descriptions. The internal researcher based the draft case story on data from the following sources: 1) Steering group protocols, power point presentations, and other supporting internal documents generated between August 2006 and January 2010; 2) monthly status reports from the project from August 2006 to the end of 2009; 3) final reports of the project phases 1-3 from August 2006; 4) final reports of the project phase 4 from January 2010; and 5) personal field notes of the internal researcher collected during the entire project period from October 2002 to the end of 2010. The external researchers studied 
Full reference to this article: Jonsson, P., Rudberg, M., Holmberg, S. (2013), "Centralised supply chain planning at IKEA”, Supply Chain Management: An international journal, Vol. 18, No. 3, pp. 337-350.

DOI: http://dx.doi.org/10.1108/SCM-05-2012-0158

numerous internal documents (process descriptions, job descriptions, some of the above listed project reports and power point presentations), listened to five two-hours presentations about the IKEA planning concept, and conducted interviews in three rounds from 2007 to 2011, each round taking one to two days. The interviewees included the project manager and demand and supply planners with experience in both the old and new planning concepts. The interviews added further details to the draft case descriptions and validated them. In terms of investigating the effects of the new planning concept, quantitative performance data were generated from IKEA internal files (this data is confidential and cannot be presented in this article). The perceived effects of the two concepts and the obstacles that IKEA encountered implementing the new concept were generated from the interviews, the observations of the internal researcher, and internal project reviews.

Table 1: Data sources and research model dimensions

\begin{tabular}{|l|c|c|c|c|c|}
\hline Data sources & \multicolumn{5}{|c|}{ Dimensions } \\
\cline { 2 - 6 } & Prerequisites & $\begin{array}{l}\text { Old planning } \\
\text { concept }\end{array}$ & $\begin{array}{l}\text { New } \\
\text { planning } \\
\text { concept }\end{array}$ & Effects & Obstacles \\
\hline Internal documents and presentations & $\mathrm{X}$ & $\mathrm{X}$ & $\mathrm{X}$ & $\mathrm{X}$ & $\mathrm{X}$ \\
\hline Observations & & $\mathrm{X}$ & $\mathrm{X}$ & $\mathrm{X}$ & $\mathrm{X}$ \\
\hline Demand and supply planner interviews & & $\mathrm{X}$ & $\mathrm{X}$ & $\mathrm{X}$ & $\mathrm{X}$ \\
\hline Project manager interviews & $\mathrm{X}$ & $\mathrm{X}$ & $\mathrm{X}$ & $\mathrm{X}$ & $\mathrm{X}$ \\
\hline
\end{tabular}

\subsection{Data analysis}

The conceptual framework, research questions and case descriptions of the old and new concepts were used as input to the data analysis. The output of the analysis contains a number of proposed relationships. As such, the approach followed a theory-generation procedure (Eisenhardt, 1989). The process was, however, not straightforward. Preliminary analyses were carried out during the years of data collection, which resulted in several iterations in which new literature and empirical data were collected. These are the five main steps of the data analysis:

1. Writing up case descriptions of the old and new planning concepts, using the process, organization and planning system structure outlined in the literature review. First, the internal researcher wrote draft descriptions. Then, the external researchers added and modified data and structured the descriptions according to the centralised planning dimensions. Finally, the internal researcher validated the descriptions. 
Full reference to this article: Jonsson, P., Rudberg, M., Holmberg, S. (2013), "Centralised supply chain planning at IKEA", Supply Chain Management: An international journal, Vol. 18, No. 3, pp. 337-350.

DOI: http://dx.doi.org/10.1108/SCM-05-2012-0158

2. Describing IKEA's supply chain context and relating it to the centralised supply chain planning prerequisites defined in the literature review.

This was done by the external researchers, and validated by the internal researcher.

3. Identifying, grouping and relating centralised planning effects.

First, a gross list of effects was generated. Thereafter, relationships between the effects and the three centralised planning dimensions were identified. The gross list and the relationships between the effects were developed in an iterative way. New literature was considered after the preliminary identification of effects and relationships. The final effects and relationships were settled after a couple of iterations. This was done by the external researchers, and validated by the internal researcher.

4. Identifying obstacles for implementing the new centralised planning concept. The internal researcher developed a preliminary gross list and description of obstacles. The external researchers structured and shaped a final list of obstacles and relationships following a procedure similar to that used for effects.

5. Validating the final case descriptions and conclusions.

The internal researcher and a senior manager at IKEA read and validated the final case descriptions and conclusions. Some minor modifications were made.

\subsection{Participatory research}

Because one of the researchers had been actively involved in the transition of the case company, facets of action research (Westbrook, 1995; Coughlan and Coghlan, 2002) and participatory research (Bryman and Bell, 2011) have been used. Our approach is not an action research approach, according to its most strict definitions because there was not a feedback loop from the researchers' data analysis to the IKEA project. The only feedback has been received through the internal researcher's involvement. No one at IKEA, except for the interviewees and a senior manager, knew about the research project. The analysis has, thus, been collaborative in the sense that the IKEA project manager, who knows the organization the best, has been involved. But it has not been collaborative in the sense that the research analysis has guided the IKEA implementation process. Because the research project was not an official IKEA project and only known to a few people at IKEA, we also believe that the Hawthorne effect (internal researcher's involvement affecting the behaviour and effects) is not a problem. Another possible validity problem of action research is lack of impartiality on the part of the researcher, which can result in biased case stories (Coughlan and Coghlan, 
Full reference to this article: Jonsson, P., Rudberg, M., Holmberg, S. (2013), "Centralised supply chain planning at IKEA", Supply Chain Management: An international journal, Vol. 18, No. 3, pp. 337-350.

DOI: http://dx.doi.org/10.1108/SCM-05-2012-0158

2002). Having two external researchers made it possible to maintain objectivity. They have taken an outside-in perspective at all times, questioning and validating the story generated by the internal researcher. They did not participate in internal project meetings, but did review internal documents, conduct interviews with IKEA personnel, and relate the IKEA case to the literature. We, thus, believe the participatory, action research-oriented involvement of the internal researcher has given us important insights and deep understanding of the IKEA planning concept and its effects and obstacles. The external researchers' involvement and roles have made it possible to maintain an objective perspective and generate valid case understanding.

\section{Case study}

This section describes IKEA's supply chain characteristics, and the characteristics and effects of the old and new planning concepts.

\subsection{IKEA's supply chain characteristics}

IKEA is a leading international home furnishing company. With its vision to "create a better everyday life for the many people”, the company has reached annual sales of $€ 23.1$ billion and has some 127,000 employees ${ }^{1}$. IKEA has more than 620 million visitors per year in the 280 stores all over the world run by franchisees inside the IKEA Group (with a further 34 stores owned and run by franchisees outside the IKEA Group). In addition, some 712 million visitors are tracked entering the IKEA website. IKEA's main marketing channel is its catalogue, with 197 million copies (in 61 different editions and 29 different languages) being distributed worldwide. The catalogue displays more than 9,500 items.

IKEA's supply chain has a global spread with both sales and purchasing in all major regions of the world. The stores, which are divided into three geographical areas, are supplied through 30 distribution centres and by some 1,400 suppliers in 55 countries. More than half of the sales volume is distributed directly from suppliers to stores. In terms of supply (purchasing), Europe stands for $62 \%$ (Poland being the largest purchasing area), followed by Asia with $34 \%$ (China largest), and North America with $4 \%$. The majority of sales are made in Europe (79 \%) with Germany being the top selling country; North America accounts for $15 \%$ of sales, and Asia/Australia together account for $6 \%$.

\footnotetext{
${ }^{1}$ All quantitative data is from IKEA’s official statistics of FY 2010.
} 
Full reference to this article: Jonsson, P., Rudberg, M., Holmberg, S. (2013), "Centralised supply chain planning at IKEA”, Supply Chain Management: An international journal, Vol. 18, No. 3, pp. 337-350.

DOI: http://dx.doi.org/10.1108/SCM-05-2012-0158

A number of factors contributed to IKEA having a planning environment that was suitable for a centralised planning approach (see Section 6.1). It has a high pace of growth, planning to open 10-20 new stores every year and a goal to double sales every fifth year. In addition, given the many stores and warehouses and the fact that 20-25\% of its assortment can change from year to year, supply chain planning is a challenge. IKEA only owns part of the capacity in its supply chain in terms of the DCs and the Swedwood Group (making up about 8-9\% of the purchase value). IKEA's supply chain is to some extent vertically integrated and is mainly made-to-stock (MTS), with only a limited range that is made-to-(customer)orders. The entire supply chain is heavily dependent on forecasts and the products would typically be classified as functional (Fisher, 1997).

\subsection{Overview of the old planning concept}

In the old planning concept, the regions and the stores had a great deal of power and a high degree of local freedom in terms of planning and placing replenishment orders. Because of frequent shortages, some regions purposely overestimated demand to ensure delivery, which led to imbalance in demand coverage. Some markets suffered from stock-outs for long periods, whereas other markets ended up with obsolete inventories. Forecasting was done on a regional level with approximately 120 people using different methods to reach different goals. In terms of capacity planning, the different parts of the supply chain (stores, warehouses, regions, etc.) tried to optimise their own function, leading to imbalanced supply plans with a low and unstable total throughput and long replenishment times for the supply chain as a whole. Several in-house-developed legacy systems were used to support the planning, and data was transferred as flat files using an in-house-designed data routing system. At the time, IKEA had an old patchwork of software systems and applications, further contributing to the fragmented and modified planning procedures and lack of proper data management.

When it evaluated its old planning situation, IKEA identified several problems with its approach. The supply chain had a functional orientation with limited transparency between functions and sub-processes, leading to reactive and unsynchronised planning behaviour. Several different planning systems (software) were being used in parallel. Planners did extensive manual work because of the lack of standardised software support and standardised working methods. This made it difficult to secure high planning information quality and stock balances, and lead times were considered unreliable. Hence, there was a lack of trust and communication between different parts of the supply chain. Other supply chain performance problems were difficulties having personnel pay attention to data maintenance, a lack of 
Full reference to this article: Jonsson, P., Rudberg, M., Holmberg, S. (2013), "Centralised supply chain planning at IKEA”, Supply Chain Management: An international journal, Vol. 18, No. 3, pp. 337-350.

DOI: http://dx.doi.org/10.1108/SCM-05-2012-0158

proper follow-up tools to monitor forecast deviations, hard to change mindsets among users, and no synchronisation of order and stock data.

\subsection{Overview of the new planning concept}

To overcome this difficult situation, IKEA initiated a programme aiming at implementing a new planning concept to take better control of its supply chain and to enhance delivery service and costs. This concept is an integrated, global planning process, which is outlined in Figure 2, and is formally located in a central planning function called IKEA of Sweden. IKEA of Sweden supervises the IKEA universe and develops long-term marketing, logistics, and purchasing strategies. IKEA of Sweden greatly influences the decisions concerning the number of items being carried, purchasing, suppliers, distribution, store coordination, and so forth. The global planning process starts with the sales and demand planning (1 in Figure 2) which sets the frames and generates future demand data for IKEA's 12 business areas. The demand data is thereafter input to the global materials planning process (2), which in turn drives the supplier capacity and load planning processes (3) and the planning of the distribution supply chain (transport, warehouse, and store planning; 4a-c in Figure 2). (Note that this article does not discuss the operational distribution supply chain, i.e., transport, warehouse and store planning (4a-c), or the commercial sales planning.)

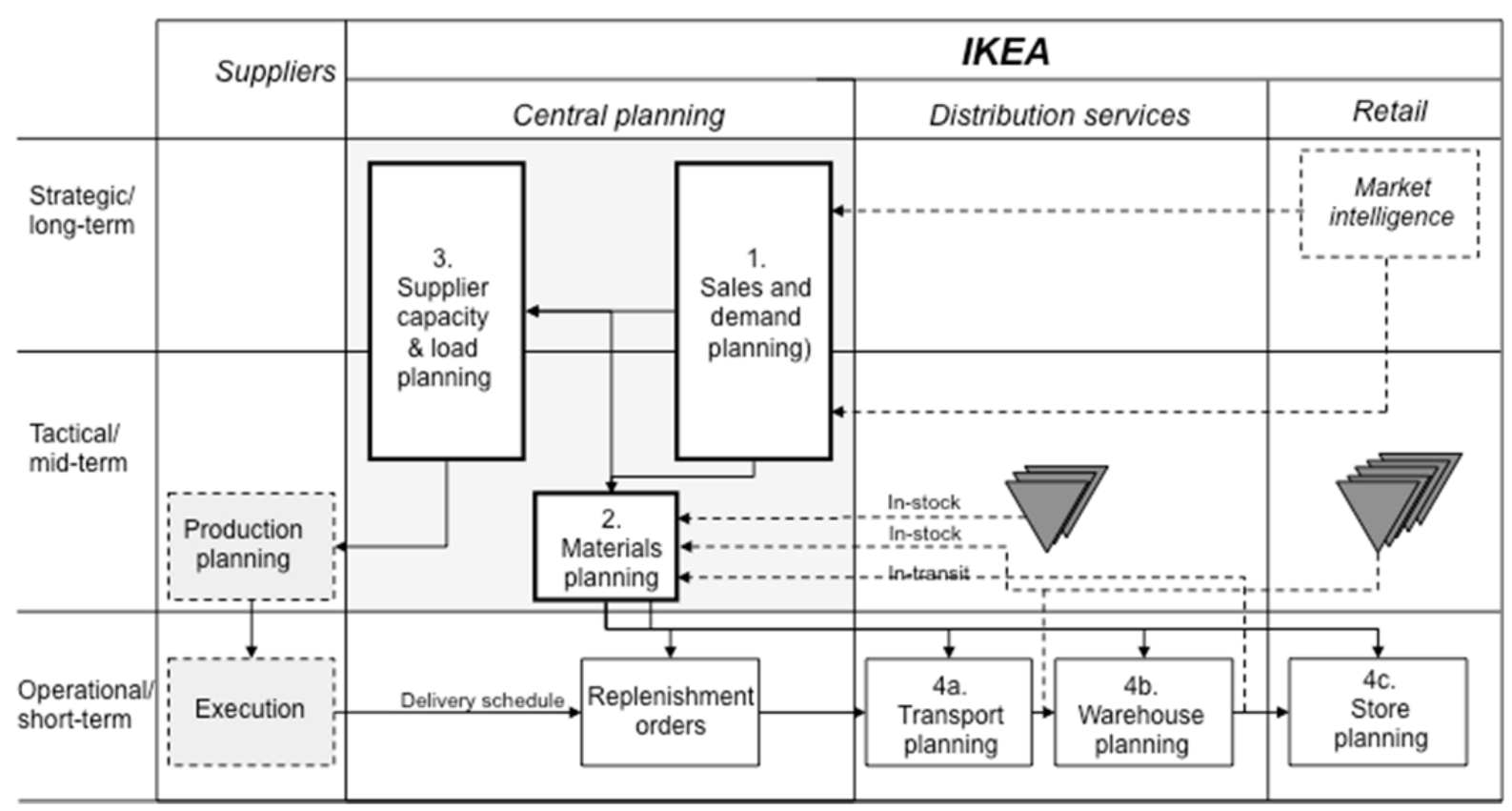

Figure 2. IKEA’s global supply chain planning processes 
Full reference to this article: Jonsson, P., Rudberg, M., Holmberg, S. (2013), "Centralised supply chain planning at IKEA”, Supply Chain Management: An international journal, Vol. 18, No. 3, pp. 337-350.

DOI: http://dx.doi.org/10.1108/SCM-05-2012-0158

IKEA developed its centralised planning concept in several stages (Figure 3). It first focused on demand planning, with new demand planning software being fully implemented in 2003. It next focused on improving materials planning, working first on the supplier-to-DC flow, with new fulfilment software being fully implemented in 2006. IKEA then expanded the fulfilment functionality to cover the entire flow from supplier, via DC, to store (including direct deliveries); it fully implemented this in 2011. IKEA also conducted the specialisation and centralisation of the planning organization in stages. In 2007, IKEA split the former supply planners group, which in the old planning concept had responsibility for both demand and materials planning, into two: demand planners, which has demand planning responsibilities and need planners, which has materials planning responsibilities. In 2009, IKEA finalized the centralisation of the demand and need planners within IKEA of Sweden.

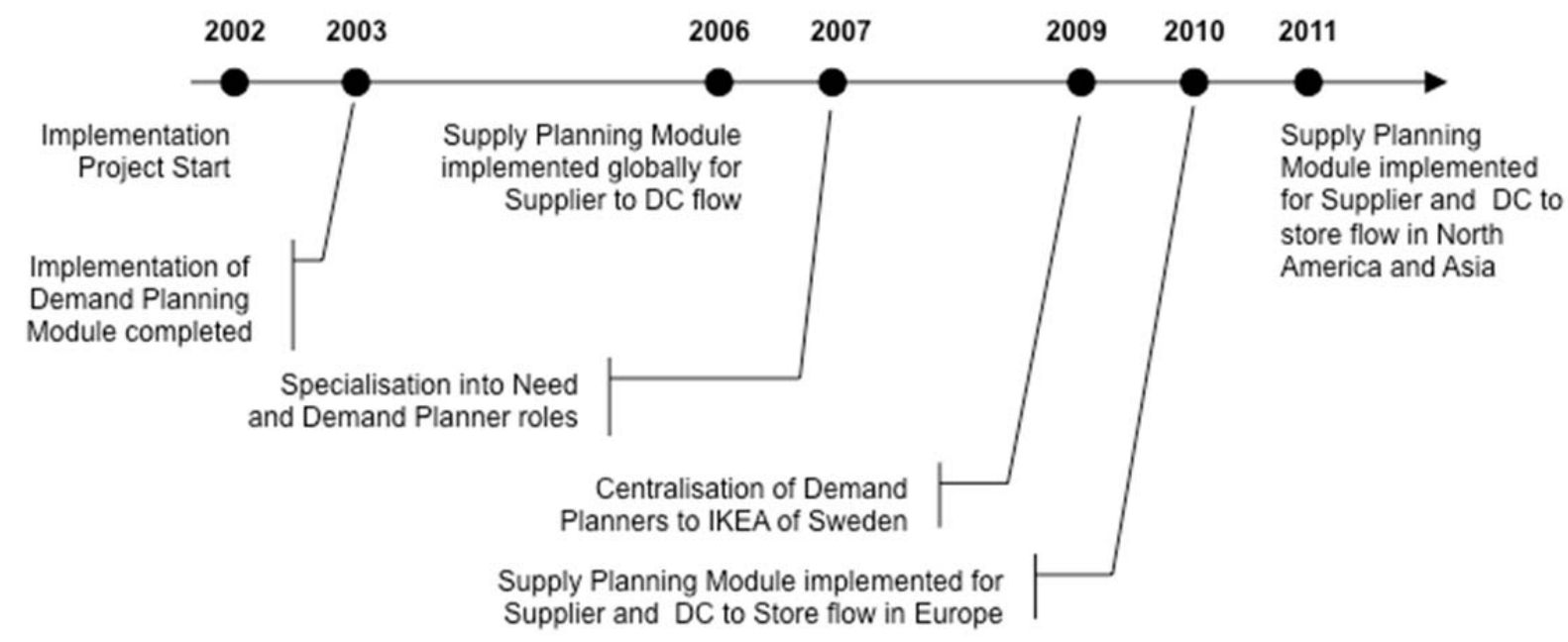

Figure 3. Implementation steps of IKEA’s global supply chain planning concept

\subsubsection{New planning processes}

The demand planning process (1 in Figure 2) consists of two sub-processes: sales frame planning, which takes a long-term and top-down perspective, and tactical forecasting process, which takes a short-term and bottom-up perspective. Sales frame planning is done on fiveyear rolling horizon based on aggregate sales volumes and is updated three times per year. Tactical forecasting is done weekly on an 84-week rolling horizon based on selling volumes at the store level (i.e., SKU level). The two sub-processes are combined on a regular basis in a 
Full reference to this article: Jonsson, P., Rudberg, M., Holmberg, S. (2013), "Centralised supply chain planning at IKEA”, Supply Chain Management: An international journal, Vol. 18, No. 3, pp. 337-350.

DOI: http://dx.doi.org/10.1108/SCM-05-2012-0158

pyramid forecasting approach in which the plans generated in the two processes are reconciled into one set of figures, which are used as demand data for the entire supply chain.

The demand planning process drives the supply planning processes, including materials planning and supplier capacity and load planning (2 and 3 in Figure 2). The materials planning process results in replenishment plans at stores and warehouses and from suppliers. Forecasts are netted in two levels: first at the store level and thereafter at the DC Group level. The netted volumes are divided between suppliers based on a so-called Supplier Matrix that determines the split of volumes between different suppliers. A daily planning frequency is used for the near future, whereas the full planning horizon (84 weeks) is updated weekly.

After this, the supplier load planning process allocates volumes on an 18-month horizon to make sure that committed volumes towards the suppliers are fulfilled and that no supplier is overloaded. The suppliers tell IKEA their capacity limit, and IKEA sometimes commits to provide a supplier with a guaranteed volume. IKEA decides whether to increase or decrease the suppliers' volumes and when necessary to adjust supplier matrices. The weekly short-term supplier capacity planning at IKEA includes load levelling between weeks on a six-months horizon so as to always fulfil the committed volumes (which includes shifting volumes between different suppliers, if necessary), and stay within the capacity limits. Exceptions are generated when there is a capacity overload or the load is below the commitment levels.

\subsubsection{New planning organization}

The demand planning process involves three organizational units: corporate management, business area management, and a central forecasting team at IKEA of Sweden. The sales frame planning starts with the overall sales forecast made by the corporate management; business area managers provide forecasts in terms of sales volumes, taking into account their business area's growth plans and ambitions. The approximately 30 demand planners are active in the tactical forecasting process, each one forecasting for part of the assortment, and also involved in the sales frame planning because they translate the reconciled forecast into a sales forecast on the SKU level. In addition, the demand planners are responsible for the global sales forecast accuracy, product range changes, and development of the forecast methodologies.

The approximately 70 need planners are responsible for matching the materials planning with the capacity planning for the entire supply chain. The need planners together with a couple of other organizational units (e.g., business area specialists), are also responsible for controlling service and stock levels in the stores and distribution centres while keeping track of the 
Full reference to this article: Jonsson, P., Rudberg, M., Holmberg, S. (2013), "Centralised supply chain planning at IKEA”, Supply Chain Management: An international journal, Vol. 18, No. 3, pp. 337-350.

DOI: http://dx.doi.org/10.1108/SCM-05-2012-0158

overall stock levels in the total supply chain. They mainly focus on the tactical planning level, while business area specialists focus on the operational planning and execution. The need planners have a key role in the global materials planning process of balancing the global requirement and capacity per supplier/category/material and are also responsible for dealing with any exception and capacity actions.

\subsubsection{New planning system software support}

To support the demand and need planners in its integrated planning processes, IKEA implemented APS system software. However, the planning processes do not fully use the APS system, but rather a mix of ERP, APS, and legacy systems, with Access and Excel being used to support the planning processes to various extents. No standard planning software is used to support the sales frame planning. Nevertheless, the tactical forecasting process is supported by standardised APS system software. Recently, IKEA took further steps to better connect the sales planning process with the demand planning process, in which new working methods have been implemented supported by the new planning system modules. The materials planning process and the supplier capacity and load planning process are also supported by standardised APS software. In some cases, the process is conducted with the support of a load levelling function in the planning system and in some other cases performed manually by the need planners.

\section{Case Analysis}

The following section provides an analysis of the effects of the new centralised supply chain planning concept and the obstacles to its implementation.

\subsection{Planning processes effects and obstacles}

The first step in developing the new centralised concept was to design standardised planning processes and establish standardised working methods that strived towards a common supply chain objective. With its sales frame planning already centralised and following fairly standardised working methods, IKEA was able to establish both supply chain integration (by concentrating planning responsibilities to one location) and hierarchical integration (by reconciling the sales frame and the tactical forecast) for all supply chain planning processes. This change integrated demand with supply all the way from the stores to the suppliers. The new processes increased forecast accuracy, reduced safety stock levels (with increased or equal service levels), and increased supply chain visibility. In addition to vertically integrating the supply chain, the new planning processes also enhanced the hierarchical integration, 
Full reference to this article: Jonsson, P., Rudberg, M., Holmberg, S. (2013), "Centralised supply chain planning at IKEA”, Supply Chain Management: An international journal, Vol. 18, No. 3, pp. 337-350.

DOI: http://dx.doi.org/10.1108/SCM-05-2012-0158

which in combination with a centralised planning organization paved the way for implementing standardised software support. This forced planners to adhere to established working methods.

Despite the positive effects of centralisation, supply plan accuracy was still low in 2011. This happened mainly because the forecast accuracy was not high enough (especially for new products), manual interventions were made to plans, and everyone did not establish and follow standardised working methods.

\subsection{Planning organization effects and obstacles}

Its new organizational design and function is key for IKEA in carrying out its global planning concept in a standardised way. Centralising the authority and control of the planning processes has given IKEA a global view of its supply chain. The establishment of the two centralised planner positions not only created the necessary specialist competence in demand and materials planning, but also made it cost efficient and practically possible to carry out the planning processes in a standardised way. It also led to common learning and continuous improvement of the processes and working methods within the group. It stimulated discussions between demand and need planners about common objects and issues, further strengthening the holistic view of the supply chain. There are several examples of areas with proactive working methods and a continuous and close dialogue occurring between need planners, demand planners, and other parts of the central organization, which allows potential problems and deviations from plan and working methods to be proactively identified and corrected. Furthermore, by adding the need planners, IKEA centralised responsibility for supply planning and demand fulfilment in one group of planners, reducing the imbalances and local sub-optimisation in the supply chain.

Some problems have occurred in implementing the new global planning concept and working methods, both for the central organization and for organizations and individuals not belonging to the central organization (e.g., store and sales representatives interacting with the processes). One difficulty was that the demand and need planners have different educational background and experience. In addition, during implementation IKEA identified problems such as insufficient end-user training and support, insufficient knowledge and involvement on the part of line management, and the new systems not being the main applications for some of the organizations and individuals. Some people had difficulties adhering to a common and standardised way of working, partly because of difficulties adjusting to the new software. 
Full reference to this article: Jonsson, P., Rudberg, M., Holmberg, S. (2013), "Centralised supply chain planning at IKEA”, Supply Chain Management: An international journal, Vol. 18, No. 3, pp. 337-350.

DOI: http://dx.doi.org/10.1108/SCM-05-2012-0158

While some regional differences exist, for example, in the levels of employee turnover, which has an impact on the performances of the organization, most problems exist globally.

\subsection{Planning systems effects and obstacles}

The planning system issues are related to the planning software modules used and the quality of the input data. The demand planners use the demand planning module in the tactical forecasting process and the need planners use the supply planning module in the materials planning and the supplier capacity planning process (Figure 2). The supply planning module also supports other roles in IKEA's planning organization with accurate and up-to-date information on net requirements, stock levels, safety stock calculations, and replenishment needs. The APS system modules offer the possibility of carrying out frequent quantitative forecasting, of aggregating and disaggregating forecasts, and of distribution requirements planning; it also has a user friendly interface, which allows for customised visualisation- and exception-based working methods. The forecasting software, in combination with organizational changes, made it possible for IKEA to reduce the number of forecasters from 120 to around 30, and, at the same time, increase average forecast accuracy. The software implementation also facilitated the implementation of a centralised planning organization and standardised planning processes. Furthermore, the software forced the demand planners and need planners to adopt the standardised planning processes and working methods for a variety of functions such as establishing time fences, forecasting methods, monitoring, safety stock calculation and updating the database regularly.

Problems that can be related to the planning systems and their use mainly concern functionality, for example, lack of support for capacity planning for DCs, stores, or transport. As a result, in-house developed legacy systems are still used and spreadsheets are used as planning tools in some less standardised processes and in case the APS system modules' functionality is not sufficient. In addition, it was realised that some planners lacked knowledge about IKEA's supply chain and how the supply chain itself affected the possibilities for planning effectively. Several data quality problems were also identified in the early phases of the new concept's implementation. Some still remain, constraining the positive effects of the new concept. The most severe data quality problems are insufficient maintenance of lead time data, problems with in-transit and stock data synchronisation, and insufficient quality of master data. The new planning systems, in combination with the new planning processes and organization, helped IKEA detect these, and other, problems and identify the means to solve these obstacles. 
Full reference to this article: Jonsson, P., Rudberg, M., Holmberg, S. (2013), "Centralised supply chain planning at IKEA”, Supply Chain Management: An international journal, Vol. 18, No. 3, pp. 337-350.

DOI: http://dx.doi.org/10.1108/SCM-05-2012-0158

\section{Discussion}

Based on the literature review and the case study, the conceptual research framework in Figure 1 is refined, with 14 relationships (Figure 4). This is discussed in this section.

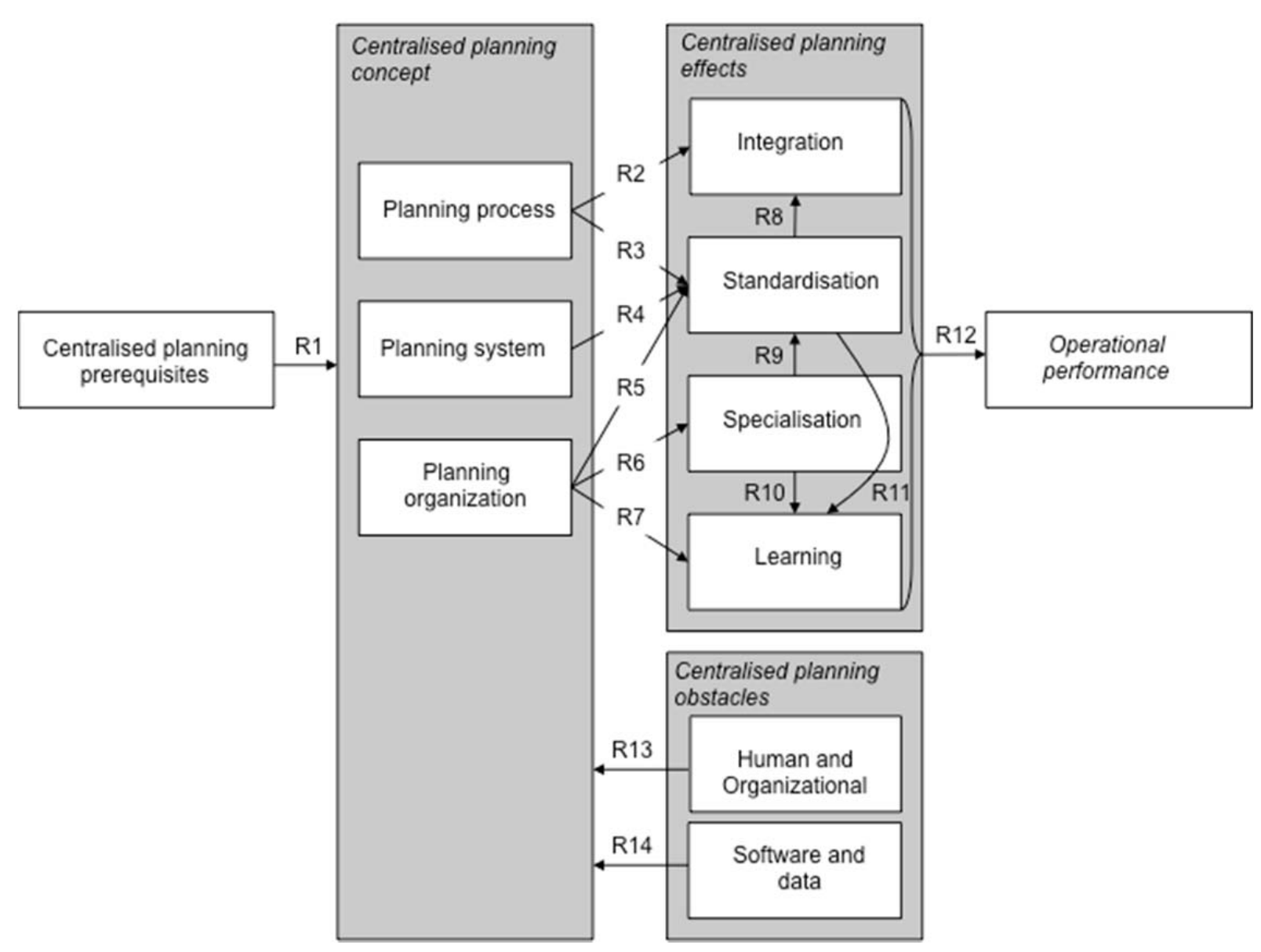

Figure 4. Relationships between prerequisites, the planning concept, its effects and its operational performance.

\subsection{The prerequisites for centralised planning}

IKEA has the prerequisites necessary (R1 in Figure 4) to implement and benefit from a centralised planning concept, as shown in a comparison of the summary of the findings from the literature with those of the case study analysis (Table 2). The IKEA supply chain is large, dispersed and global, which in the past had made it fragmented, with many local organizations striving to reach different goals. Local optimisation resulted in global inefficiency. Because IKEA's products would be classified as functional, Fisher (1997) would argue that the company should strive for a physically efficient supply chain and vertical 
Full reference to this article: Jonsson, P., Rudberg, M., Holmberg, S. (2013), "Centralised supply chain planning at IKEA”, Supply Chain Management: An international journal, Vol. 18, No. 3, pp. 337-350.

DOI: http://dx.doi.org/10.1108/SCM-05-2012-0158

integration. One could argue that the IKEA supply chain is not fully vertically integrated and that the supply chain includes many different organizations. Yet, the supply chain is fully integrated downstream and many IKEA suppliers have IKEA as their sole or major customer or, in some instances, are owned, in part or in full, by IKEA. Hence, from a planning perspective, IKEA can treat the supply chain as being vertically integrated, which gives it the power to determine the rules and procedures for supply chain planning. Given these prerequisites, IKEA seemed well suited to implement a centralised supply chain planning approach.

Table 2: Prerequisites for centralised supply chain planning

\begin{tabular}{|l|l|}
\hline Literature findings & IKEA case study findings \\
\hline $\begin{array}{l}\text { Functional products striving for a physically efficient } \\
\text { supply chain (Fisher, 1997) }\end{array}$ & $\begin{array}{l}\text { The products are functional and IKEA strives for } \\
\text { an efficient, low cost supply chain. }\end{array}$ \\
\hline $\begin{array}{l}\text { Vertically integrated supply chain (Hayes and } \\
\text { Schmenner, 1978; De Meyer and Vereecke, 1994; Rice } \\
\text { and Hoppe, 2001; Marcotte et al, 2009) }\end{array}$ & $\begin{array}{l}\text { While not under full ownership, IKEA is vertically } \\
\text { integrated through partnerships, partial ownership, } \\
\text { and long-term contracts. }\end{array}$ \\
\hline $\begin{array}{l}\text { Dominating organisation (Rudberg and Olhager, 2003) in } \\
\text { manufacturing, warehouses and retailers (APICS, 2011) }\end{array}$ & $\begin{array}{l}\text { While not single organization, it is a a dominating } \\
\text { organisation with full ownership of warehouses } \\
\text { (manufacturing). }\end{array}$ \\
\hline $\begin{array}{l}\text { Power and competence to enforce the implementation } \\
\text { (Pibernik and Sucky, 2006), especially concerning the } \\
\text { importance of corporate staff (Marcotte et al., 2009) }\end{array}$ & $\begin{array}{l}\text { IKEA has the power and a a high degree of } \\
\text { competence with SCM, and the centralised } \\
\text { planning organisation plays an active role in the }\end{array}$ \\
\hline new concept.
\end{tabular}

\subsection{The centralised planning concept and its effects}

Research question 1 asked "What effects can be expected when centralising supply chain planning?”. This study shows that the redesigned planning processes improved supply chain 
Full reference to this article: Jonsson, P., Rudberg, M., Holmberg, S. (2013), "Centralised supply chain planning at IKEA”, Supply Chain Management: An international journal, Vol. 18, No. 3, pp. 337-350.

DOI: http://dx.doi.org/10.1108/SCM-05-2012-0158

integration (R2 in Figure 4), both in terms of the supply chain from suppliers to stores and in terms of hierarchical planning from strategic to tactical to operational planning. The new planning processes' bi-directional integration has in turn created a supply chain in which supply better matches demand. An important benefit of this is improved supply chain visibility (Dreyer et al., 2009), even though data quality deficiencies sometimes limit its effect. The new planning processes have also created a higher degree of standardisation (R3) through the establishment of standardised working methods and improved planning functionality, which in turn led to the possibility of implementing a higher degree of automated planning activities through the implementation of new planning systems (R4). Researchers (Bendoly and Jacobs, 2004; Jonsson et al., 2007) have identified the links between information systems, standardisation and performance. This study further shows that increased standardisation in planning processes systems may lead to improved performance. The new planning organization further facilitated standardisation (R5), which led to reduced number of planners and faster planning. Having the planning specialists (demand and need planners) work together in a co-located centralised organization created a higher degree of specialisation (R6) and established an environment based on learning (R7). Such positive indirect learning effects were also identified by Ivert and Jonsson (2010). The standardisation of working methods, work flows and processes also enhanced the possibilities of integration (R8), because all parties in the supply chain were forced to adhere to the same practices. Establishing the two new specialist planning roles and locating them in one place made it easier for IKEA to implement standardised working methods (R9). The concentration of planning responsibility also created a critical mass of specialists at one location, paving the way for additional learning effects (R10). Somewhat counterintuitively, standardisation also had a positive impact on individual and organizational learning (R11). By standardising working methods and enforcing their use, IKEA continuously improved its working methods, and enabled new ideas to be discussed and implemented. This is also likely facilitated by all planners being concentrated to one location. In summary, the implementation of the new centralised supply chain concept had positive effects in terms of integration, standardisation, specialization and learning effects - issues that IKEA was striving to address in the process of improving its supply chain management.

The effects on performance identified in the literature were all apparent in the IKEA case (R12), as is summarized in Table 3.

Table 3: Effects on operational performance 
Full reference to this article: Jonsson, P., Rudberg, M., Holmberg, S. (2013), "Centralised supply chain planning at IKEA”, Supply Chain Management: An international journal, Vol. 18, No. 3, pp. 337-350.

DOI: http://dx.doi.org/10.1108/SCM-05-2012-0158

\begin{tabular}{|c|c|}
\hline Literature findings & IKEA case study findings \\
\hline $\begin{array}{l}\text { Better meet global supply chain objectives/common supply } \\
\text { chain plans (Jonsson et al., 2007; Marcotte et al., 2009) }\end{array}$ & $\begin{array}{l}\text { IKEA today has one common supply chain plan } \\
\text { that strives towards global IKEA objectives. }\end{array}$ \\
\hline $\begin{array}{l}\text { Increased supply chain efficiency (Fisher, 1997; Fiala, } \\
\text { 2005) }\end{array}$ & $\begin{array}{l}\text { More reliable plans lead to more efficient } \\
\text { production, transportation and replenishment. } \\
\text { The planning is also more efficient. }\end{array}$ \\
\hline $\begin{array}{l}\text { Low cost (Hayes and Schmenner, 1978; Business } \\
\text { International, 1985;Snow et al, 1993; DuBois et al, 1993; } \\
\text { De Meyer and Vereecke, 1994; Fisher, 1997; Bartlett and } \\
\text { Ghoshal, 1998; Rudberg, 2004; Pibernik and Sucky, 2007, } \\
\text { Rudberg and Thulin, 2009) }\end{array}$ & $\begin{array}{l}\text { Measurable effects are that stock levels are } \\
\text { down and that they have less obsolete } \\
\text { inventory*. Besides this, IKEA has reduced the } \\
\text { planning work force and provide better plans to } \\
\text { suppliers leading to positive long-term effects on } \\
\text { cost. }\end{array}$ \\
\hline $\begin{array}{l}\text { Higher delivery performance/on-time delivery (Snow et al, } \\
\text { 1993; Fisher, 1997; Rudberg and Thulin, 2009) }\end{array}$ & Delivery performance has increased*. \\
\hline $\begin{array}{l}\text { More transparent/visible demand patterns and improved } \\
\text { forecast accuracy (Dreyer et al, 2009; Rudberg and Thulin, } \\
\text { 2009; Cederborg and Rudberg, 2011) }\end{array}$ & $\begin{array}{l}\text { Demand and forecasts are entered into a } \\
\text { centralised planning system and forecast } \\
\text { accuracy has increased*. }\end{array}$ \\
\hline
\end{tabular}

*Based on confidential IKEA internal operational measures of obsolete inventory, delivery performance and forecast accuracy in 2001 and 2011.

\subsection{The centralised planning concept and its obstacles}

Research question 2 asked "What are the obstacles for implementing centralised supply chain planning?". The main obstacles identified in the case analysis can be grouped into two main types: 1) human and organizational (R13), and 2) software and data (R14). Examples of the human and organizational obstacles include difficulties in having everyone work in a standardised way according to the new process, in paying enough attention to data management, and in changing the mindsets of employees. Lack of training, knowledge and management support were identified as causes of these difficulties, but IKEA had also underestimated how difficult it would be to change the mindsets of its employees. The importance of being able to change attitudes and of managing change has been identified in previous studies (Gargeya and Brady, 2005; van Veen-Dirks and Verdaasdonk, 2009; Wiers, 
Full reference to this article: Jonsson, P., Rudberg, M., Holmberg, S. (2013), "Centralised supply chain planning at IKEA", Supply Chain Management: An international journal, Vol. 18, No. 3, pp. 337-350.

DOI: http://dx.doi.org/10.1108/SCM-05-2012-0158

2009) and is, consequently, further emphasized here. The role and involvement of the individuals taking part in the new planning approach has been identified as key for the success or failure of APS system implementations (Ivert and Jonsson, 2011). Individuals were also key facilitators or obstacles in the implementing of IKEA's supply chain planning concept.

The software and data obstacles related to a lack of employee training in software functionality, deficiencies in data quality and data management methods, and a lack of software support in some areas. Lack of planning functionality can be serious but, in line with the findings in Ivert and Jonsson (2011), is not considered the most significant obstacle in an APS system-based planning process change. Data quality deficiencies and limited IT infrastructure integration are more important obstacles. This study, consequently, supports previous studies in emphasizing the importance of good data quality (Jonsson et al., 2007; Haug and Arlbjørn, 2011) and IT infrastructure integration (Wiers, 2002) for managing APS system-based supply chain planning.

\section{Conclusion and future research}

IKEA had long realised that even though the company was doing rather well it suffered from severe problems in its supply chain planning. The old planning concept, which had resulted in a fragmented supply chain built around local decision making, was sometimes counterproductive to corporate objectives, thereby jeopardising corporate growth plans. A substantial growth in sales would make it even harder for management to make the fragmented supply chain work efficiently. Hence, a change was needed, and based on its goal of having low-cost products and an efficient supply chain, IKEA developed a new concept for centralised supply chain planning. In this paper we describe how IKEA has developed and implemented a centralised supply chain planning approach - a concept that has taken them from a fragmented decentralised management to centralised, coordinated, supply chain planning (Figure 5). Through the case analysis of planning processes, organization and software system, the research in this paper has identified necessary prerequisites for implementing centralised supply chain planning, but also effects that can be expected from such an implementation. The results also expose typical obstacles that have to be dealt with when implementing centralised supply chain planning. 
Full reference to this article: Jonsson, P., Rudberg, M., Holmberg, S. (2013), "Centralised supply chain planning at IKEA”, Supply Chain Management: An international journal, Vol. 18, No. 3, pp. 337-350.

DOI: http://dx.doi.org/10.1108/SCM-05-2012-0158

Old (fragmented) planning concept:

- Functional, local orientation with limited transparency and information sharing

- Reactive planning behavior, with extensive manual work

- Unreliable planning information, leading to a lack of trust among supply chain members.

- Fluctuating goods availability, including both over stock and shortages

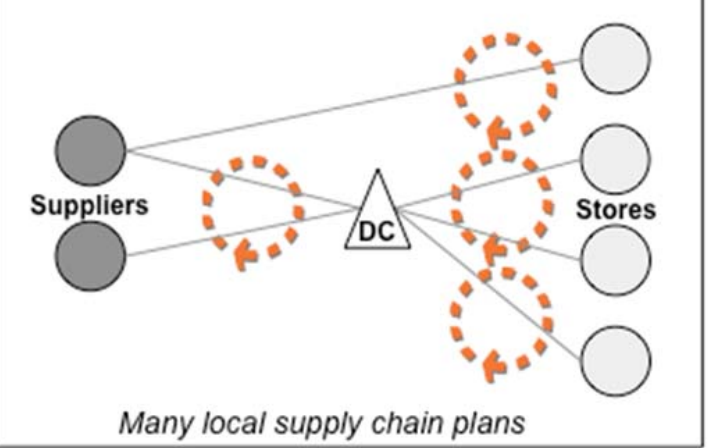

Figure 5. Summary of managerial results from implementing centralised supply chain planning.

The results of the study have a number of implications for practice and research. From a managerial perspective, the research in this paper indicates that centralised supply chain planning is important for a large and growing global supply chain that is striving for low-cost production and efficiency. Managers can also use the results of this study to analyse whether they have the necessary prerequisites in place for centralising their supply chain planning and, if so, taking into account the three perspectives of the planning processes, planning systems and planning organization when developing their own concepts. In addition, the research can aid them in tracking the expected effects and obstacles of centralisation. Turning to the research implications, the identified prerequisites for centralised supply chain planning were the following: functional products, vertical integration with a single (or dominating) organization having at least partial ownership of supply chain facilities, power and competence to enforce the implementation, and one planning domain possessing all critical planning information. The set of direct effects of centralised supply chain planning is related to following factors: supply chain integration, standardisation, specialisation, and learning effects. The case study shows how implementing centralised supply chain planning in an appropriate planning context, achieving integration, standardisation, specialisation and 
Full reference to this article: Jonsson, P., Rudberg, M., Holmberg, S. (2013), "Centralised supply chain planning at IKEA”, Supply Chain Management: An international journal, Vol. 18, No. 3, pp. 337-350.

DOI: http://dx.doi.org/10.1108/SCM-05-2012-0158

learning, leads to operational performance improvements. Identified obstacles to successfully carrying out centralised supply chain planning mainly relate to human and organizational issues, and to software and data issues.

We have provided a theoretical framework (Figure 1) that can help academics to analyse centralisation of supply chain planning and practitioners to design centralisation concepts. We tested and refined the framework through a case study and identified 14 relationships that explain the effects and obstacles of implementing centralised supply chain planning (Figure 4). Further studies are required to establish a generally valid framework, or theory, for centralised supply chain planning. More case-based studies could develop, fine-tune and generalise the identified centralised supply chain planning variables and relationships. The relationships also need to be tested through deductive approaches in wider empirical contexts, for example, through multiple case studies or surveys. More studies on implementation and change processes are also needed to fully understand how to implement a centralised planning concept and to achieve its potential benefits.

\section{References}

APICS (2011), “Supply chain management fundamentals (Module 1)”, The Certified supply chain professional (CSCP) learning system, APICS, Alexandria (USA).

Bartlett, C.A. and Ghoshal, S. (1998), Managing across borders: The transnational solution, $2^{\text {nd }}$ ed., Harvard Business School Press, Boston, MA.

Bendoly, E. and Jacobs, R. (2004), “ERP architectural/operational alignment for order processing performance, International Journal of Operations and Production Management, Vol. 24, pp. 99-117.

Berglund, M. and Karltun, J. (2007), “Human, technological and organisational aspects influencing the production scheduling process”, International Journal of Production Economics, Vol. 110, No. 1-2, pp. 160-174

Bozarth, C. (2006), "ERP implementation efforts at three firms: integrating lessons from the SISP and IT-enabled change literature”, International Journal of Operations and Production Management, Vol. 26, No. 11, pp. 1223-1239.

Bozarth, C., Warsing, D., Flynn, B. and Flynn, J. (2009). “The impact of supply chain complexity on manufacturing plant performance", Journal of Operations Management, Vol. 27, No. 1, pp. 79-93. 
Full reference to this article: Jonsson, P., Rudberg, M., Holmberg, S. (2013), "Centralised supply chain planning at IKEA”, Supply Chain Management: An international journal, Vol. 18, No. 3, pp. 337-350.

DOI: http://dx.doi.org/10.1108/SCM-05-2012-0158

Bryman, A. and Bell, E. (2011), Business research methods, Oxford University Press.

Business International. (1985), 161 more checklists: Decision making in international operations, Business International Corporation, New York, NY.

Caves, R.E. (1996), Multinational enterprise and economic analysis, $2^{\text {nd }}$ ed., Cambridge University Press, Cambridge.

Coughlan, P. and Coghlan, D. (2002), “Action research for operations management”, International Journal of Operations and Production Management, Vol. 22, No. 2, pp. 220240.

De Meyer, A. and Vereecke, A. (1994) Strategies for international manufacturing, INSEAD Working Paper Series \#94/25/SM/TM, INSEAD.

Dreyer, H. C., Alfnes, E., Strandhagen, J. O. and Thomassen, M. K. (2009), “Global supply chain control systems: A conceptual framework for the global control centre”, Production Planning \& Control, Vol. 20, No. 2, pp. 147-157.

DuBois, F.L., Toyne, B. and Oliff, M.D. (1993), "International manufacturing strategies of U.S. multinationals: A conceptual framework based on a four-industry study”, Journal of International Business Studies, Vol. 24, No. 2, pp. 307-333.

Eisenhardt, K. (1989), “Building theory from case study research”, Academy of Management Review, Vol. 14, No. 4, pp. 532-550.

Ferlie, E. and McNulty, T. (1997), "Going to market": changing patterns in the organisation and character of process research”, Scandinavian Journal of Management, Vol. 13, No. 4, pp. 367-387.

Fiala, P. (2005), "Information sharing in supply chains", Omega: International Journal of Management Science, Vol. 33, No. 5, pp. 419-423.

Fisher, M.L. (1997), "What is the right supply chain for your product?”, Harvard Business Review, Vol. 75, No. 2, pp. 105-116.

Flaherty, M.T. (1996), Global Operations Management, McGraw-Hill, New York.

Gargeya, B.V. and Brady, C. (2005), "Success and failure factors of adopting SAP in ERP system implementation”, Business Process Management Journal, Vol. 11, No. 5, pp. 501-516

Goold, H. and Campbell, A. (1987), Strategies and styles: The role of the centre in managing diversified companies, Basil Blackwell, Oxford. 
Full reference to this article: Jonsson, P., Rudberg, M., Holmberg, S. (2013), "Centralised supply chain planning at IKEA”, Supply Chain Management: An international journal, Vol. 18, No. 3, pp. 337-350.

DOI: http://dx.doi.org/10.1108/SCM-05-2012-0158

Haug, A. and Arlbjørn, J. (2011), "Barriers to master data quality”, Journal of Enterprise Information Management, Vol. 24, No. 3, pp. 288-303.

Hayes, R.H. and Schmenner, R.W. (1978), "How should you organize manufacturing?”, Harvard Business Review, Vol. 56, No. 1, pp. 105-118.

Holmström, J., Främling, K., Tuomi, J., Kärkkäinen, M. and Ala-Risku, T. (2002), "Implementing cooperation process networks", The International Journal of Logistics Management, Vol. 13, No. 2, pp. 39-50.

Ivert K, L. and Jonsson, P. (2010), “The potential benefits of advanced planning and scheduling systems in sales and operations planning”, Industrial Management \& Data Systems, Vol. 110, No. 5, pp. 659-681.

Ivert, K. L. and Jonsson P. (2011), "Problems in the onward and upward phase of APS system implementation: Why do they occur?”, International Journal of Physical Distribution and Logistics Management, Vol. 41, No. 4, pp. 343-363.

Johnston, G. and Scholes, K. (1993) Exploring corporate strategy, Prentice Hall, London.

Jonsson, P. and Mattsson, S-A. (2009), Manufacturing planning and control, McGraw-Hill, London.

Jonsson, P., Kjellsdotter, L. and Rudberg, M. (2007), ”Applying advanced planning systems for supply chain planning: three case studies”, International Journal of Physical Distribution and Logistics Management, Vol. 37, No. 10, pp. 816-834.

Lorentz, H. Öyli, J. Solakivi, T. Hälinen, H-M. and Ojala, L. (2012), "Effects of geographic dispersion on intra-firm supply chain performance” Supply Chain Management: An International Journal, Vol. 17, No. 6, pp. 611-626.

Malhotra, M. K. and Sharma, S. (2002) "Spanning the continuum between marketing and operations”, Journal of Operations Management, Vol. 20, No. 3, pp. 209-219

Marcotte, F., Grabot, B. and Affonso, R. (2009), “Cooperation models for supply chain management”, International Journal of Logistics Systems and Management, Vol. 5, No. 1-2, pp. 123-153.

Narayanan, V. and Raman, A. (2004), “Aligning incentives in supply chains”, Harvard Business Review, Vol. 82, pp. 94-102. 
Full reference to this article: Jonsson, P., Rudberg, M., Holmberg, S. (2013), "Centralised supply chain planning at IKEA”, Supply Chain Management: An international journal, Vol. 18, No. 3, pp. 337-350.

DOI: http://dx.doi.org/10.1108/SCM-05-2012-0158

Oliva, R. and Watson, N. (2011), "Cross-functional alignment in supply chain planning: A case study of sales and operations planning”, Journal of Operations Management, Vol. 29, pp. 434-448.

Pibernik, R. and Sucky, E. (2006), “Centralised and decentralised supply chain planning”, International Journal of Integrated Supply Management, Vol. 2, No. 1/2, pp. 6-27.

Pibernik, R. and Sucky, E. (2007), “An approach to inter-domain master planning in supply chains”, International journal of Production Economics, Vol. 108, pp. 200-212.

Power, D. (2005), "Supply chain management integration and implementation: a literature review”, Supply Chain Management: An International Journal, Vol. 10, No. 4, pp. 252-263.

Rice, J. and Hoppe, R. (2001), "Supply chain vs. supply chain: the hype and the reality”, Supply Chain Management Review, Vol. 5, No. 5, pp. 46-54.

Robbins, S. (1990), Organization Theory. Prentice-Hall, New York.

Rudberg, M. (2004), “Linking competitive priorities and manufacturing networks: A manufacturing strategy perspective”, International Journal of Manufacturing Technology and Management, Vol. 6, No. 1/2, pp. 55-80.

Rudberg, M. and Cederborg, O. (2011), “APS for Tactical Planning in a Steel Processing Company”, Industrial Management \& Data Systems, Vol. 111, No. 3-4, pp. 608-628.

Rudberg, M. and Olhager, J. (2003), "Manufacturing networks and supply chains: An operations strategy perspective”. Omega: International Journal of Management Science, Vol. 31, No. 1, pp. 29-39.

Rudberg, M. and Thulin, J. (2009), "Centralised supply chain master planning employing advanced planning systems”, Production Planning \& Control, Vol. 20, No. 2, pp. 158-167.

Rudberg, M. and West, B.M. (2008), "Global operations strategy: Coordinating manufacturing networks”, Omega: International Journal of Management Science, Vol. 36, pp. 91-106.

Snow, C.C., Miles, R.E. and Coleman, H.J. (1993), "Managing $21^{\text {st }}$ century network organisations”, Organisational Dynamics, Vol. 20, No. 2, pp. 5-20.

Stadtler, H. and Kilger, C., (2008), Supply chain management and advanced planning concepts, models, software and case studies, 4th ed. Berlin: Springer. 
Full reference to this article: Jonsson, P., Rudberg, M., Holmberg, S. (2013), "Centralised supply chain planning at IKEA”, Supply Chain Management: An international journal, Vol. 18, No. 3, pp. 337-350.

DOI: http://dx.doi.org/10.1108/SCM-05-2012-0158

The Economist Intelligence Unit, (1993), Organizing the new global competitor, Research Report No. I-114, New York, NY.

Van Veen-Dirks, P.M.G. and Verdaasdonk, P.J.A (2009) “The dynamic relation between management control and governance structure in a supply chain context”, Supply Chain Management: An International Journal, Vol. 14, No. 6, pp. 466-478.

Westbrook, R. (1995), “Action Research: a new paradigm for research in production and operations management”, International Journal of Operations and Production Management, Vol. 15, No. 12 pp. 6-20.

Wiers, V.C.S. (2002), “A case study on the integration of APS and ERP in a steel processing plant”, Production Planning \& Control, Vol. 13 No. 6, pp. 552-60.

Wiers, V.C.S. (2009), “The relationship between shop floor autonomy and APS implementation success: evidence from two cases”, Production Planning and Control, Vol. 20, No. 7, pp. 576-585.

Wong, C. Y., Arlbjørn, J. S. and Johansen, J. (2005), "Supply chain management practices in toy supply chains”. Supply Chain Management: An International Journal, Vol. 10, No. 5, pp. 367-378.

Wortmann, J.C., Muntslag, D.R., and Timmermans, P.J.M. (1997), Customer-driven manufacturing, Chapman \& Hall, London.

Yin, R. (2003), Case study research: Design and methods, 3rd ed., Sage Publications, Thousand Oaks, CA.

Zey-Ferrell, M. (1979), Dimensions of organisations: Environment, context, structure, process, and performance, Goodyear Publishing, Santa Monica, CA. 